

\section{List of Abbreviations}

The following abbreviations are used throughout the text for quotations from Ashwin Singh's plays.

$\mathrm{H} \quad$ To House

SS Spice ' $n$ ' Stuff

Sh Shooting

RL Reoca Light

D Duped

BBB Beyond the Big Bangs

Sw Swing

IG Into the Grey

\section{Note on Terminology}

We have chosen not to unify the authors' use of the term black so readers are encouraged to think beyond straightforward definitions. Each author uses the term in his or her own way and spells it with either a capital B or a small letter b. Likewise, authors have opted for capital or lower case letters for other ethnicities, such as white or coloured, in accordance with their specific purpose. 


\title{
Ashwin Singh: Egg or Chicken: A Writer/Director's Recipe in Interviews and Analysis
}

\author{
Deborah A Lutge
}

"Now the author is dead, and the author is Apartheid."

Zakes Mda (quoted in Naidoo, 1997: 252)

For South African Theatre context has always proved to be a factor intricately woven into our socio-political inheritance. After twenty-six years of democracy, with changed, or with fluctuating notions of what should constitute the 'polis', the enhanced significance of community, as an expression of identity and agency, is evident in the socio-cultural shifts. Aristotle advocated the notion that "man is a political animal" (Rospide \& Sorlin, 2015: 30). If this notion is accepted then, man is an essential part of the polis. In a theatrical context it is the writer who acknowledges and highlights these shifts, the director who seeks conceptual context and interpretation, and the participating audience who through discovery are enlightened by contemplating what they assume that they already unconsciously know and what they thought they understood from the new angle or perspective.

In 1994, South Africa underwent, in a single act, the most radical socio-political change of the latter half of the $20^{\text {th }}$ Century. The lines of voters queuing to make their voices heard for the first time bore testimony to this radical swing. Now the South African black voice counted. Much has been said about the impact of protest theatre as a theatre inspiring dynamic movement. Texts, literary and performance, publicised Struggle voices that echoed the call for mass solidarity. Advocacy included the mobilisation of a populace roused by songs and cries for freedom, as theatrical content contradicted white propaganda. Denialism was questioned more frequently in white theatre going circles. Segal claims Western audiences who had turned a blind eye to racial injustice, renegotiated their former global denial after the 1964 Rivonia Trials. (1964: 394-5). In South Africa, status quo options that expected segregated audiences, were no longer perceived as logical, and simply not tolerated by independence in 1994 (Johnson, 1994). Theatre is no longer just a question of preaching to the politically converted but an irrevocable distancing from historical cultural enclaves. More adventurous audiences engaged in a honeymoon period as long as it meant attending the theatre in their region. This is not to deny that even with the integration of audiences, the denialism of many audience members attending the 'close your eyes and think of England' theatre into the 90s and beyond persisted as an escape from the diabolical economic divisions evident, as theatre continued to be divided along cultural lines by choice rather than prescription. 
The insinuation of locale in the reference to Durban and the communal portrait of being 'Indian in Durban' in the title of Singh's anthology, signify cultural exclusivity too. Therefore, it is noteworthy that in the production of these Singh plays, the constant intracultural interrelationship of writer, directors, and audiences exerted a cross-cultural appeal. South Africans related to Singh's sardonic critique on South African socio-politics, his observation of character through dialogic subliminal messaging, and his kaleidoscopic interpretation of regional interrelationships. Sometimes in Singh's work what is not said is as powerful as what is said. The discussion between Sibusiso and Kajol in To House inscribes the notion of the shifting parameters of the extended 'Indian' family when Kajol says in relation to 'circulating' her mother between family members: "This is what Indians are becoming." (H 48). Kajol reflects on the varied gender expectations in her discussion of her brother touring while she herself retains the role of the duty-bound daughter ( $\mathrm{H} 48$ ). Sibusiso suggests an old age home and Kajol recognizes the suggestion as an attempt to avoid responsibility, calling this action "the white thing to do" (H 48). The inference is that white colonials remain in denial, refusing to acknowledge their responsibility in the apartheid debacle, while abdicating all guilt in the colonial privilege experienced. Kajol insinuates her sense of responsibility to her mother and Sibusiso attempts to dissuade Kajol from proposing her mother move in with the couple, by playing the race card: "Hey I can take care of myself. (Awkward pause.) You think your mother is going to live with a black man?” (H 49). Difference is attributed to culture, to race, and to the degree of struggle and success and Sibusiso confirms his acceptance as impacted by the polite gentility of Kajol's mother and his successful position as a lawyer (H 49). Culture, race and socio-economic class are inextricably bound.

As South Africans contemplate the reimagining of the participating roles between writer, director and audience, the socio-political links are again clearly visible. The pandemic has radically changed the logistics and operation of live performance and may indeed change the method of delivery, yet the constant interdependence of writer, director, and audience continues as an abacus awaiting the reinterpretation in a changed socio-political context. Notwithstanding global changes, a shift does not negate a past - it grows out of it. Society's constant companion is flux, a fluidity complicating the tracing of 'roots'. This is not limited to South Africa or to the South African diaspora but flux is a common feature resulting in a complex interweaving of world dynamics. The complexities of understanding 'our present', requires underpinning our understanding by identifying root causes, for the underbelly of the collective has consequences that determine future accountability. The vulnerable and the weak will determine on what future society will make pronouncements. Further, future accountability is dependent on our acknowledgement of past displacement, marginalisation and migration, on what is justified, what is hidden, and what condemned. Past rather than present reception provides the catalyst for the manner in which 
social inequities are internalized. Our accountability in the future presupposes an assumption of the way we experience consequences from the past, rather than on an engagement with the past, since the present is attempting to move forward. Socially internalized injustices do not die, they emerge therapeutically through the guidance provided by writers or playwrights attempting to conscientise community or society at large. This experiential trajectory configures texts differently and differentiates written text from performance text and from textual reception. But what if the creator and interpreter are the same person? If so, how does this make a notable difference? In a theatrical context does the directorial eye transliterate the writing during the creative phase or does the finished text firmly entrench directorial concepts derived from a familiarity with the creative writing process? Is the finished product then crafted by writer or director? Is this a linear or a spherical construct?

A dialectical answer (that of Hegel and Marx) is that the egg and chicken exist in a dialectical relationship; the problem according to this answer, is that we are approaching an organic/dialectical relationship with the mindset of formal logic, i.e. linear cause-and-effect. Using this mindset, we reach a paradox, for we only see it in terms of 'this caused that.' To reach the true nature of this relationship, we have to admit the fact that the egg creates the chicken just as much as the chicken creates the egg (Hodgson, 1986: 219). But playscripts are distinctive from other forms of creative writing for without this kind of text the director of scriptbased works has no blueprint and without the director or an astute reader, the playwright's script remains a blueprint without a building.

\section{Looking at the 2jst Century}

In Joseph Heller's 1961 novel the character Yossarian, in attempting to avoid flight, requires proof of insanity, which if produced would conversely prove sanity. Catch-22 inscribes our history, as well as our quest to contextualise our existence, just as it inscribed the Aristotelian premise. Aristotle too grappled with the notion of roots. He argued that if the first human had been born without father or mother - it would have contradicted natural order as a first egg presupposes a first bird, and a bird comes from an egg (Waller, 1998: 851-853).

The relationship between playwright and director is so interwoven that it reminds me very much of the egg-chicken conundrum: for without a play the director cannot direct, and without a director the play's function is incomplete. This paradoxical notion applies broadly to our attempts to deconstruct the social milieu. The scales in our argument are evenly balanced between our logical conceptualising of individual identity on the one hand, and cultural roots on the other. The individual is distinct from cultural roots, yet inscribed with a specific 
socio-cultural identity. Therefore, there is this quest to uncover a past that explains the meaning of present existence, in order to direct our individual future efforts, is inherent in our humanity; our identity; our agency; our roots; and our sense of Ubuntu. It is this that makes us essentially human and characters are informed by these identifiable behavioural patterns in South African theatre.

The COVID-19 global lockdown may shift historical sourcing and the shifts in theatre will grow out of how artists understood this shift contextualised within historical frameworks. Frequently, as in Mda's syllogism, authors source living material in the graves of the past. The oxymoron of South African Theatre currently lies in the notion of paradoxical poles: what might be termed a 'struggling-freemarket-system'; a democracy in search of freedom; an espousing of 'equity' and basic constitutional human rights, in a country with dysfunctional service delivery. Hence our preoccupation with history remains the vehicle of current theatre, and the same is true for Ashwin Singh's anthology Durban Dialogues, Indian Voice.

Arguably the shifts in the $21^{\text {st }}$ Century have already signalled a departure, a migration, not only from the $20^{\text {th }}$ Century mind-set, encouraged by global communication on a world-wide web, but through the transmigration of worldviews, further reconfigured by border crossings and world-wide cultural melting-pots. Wars and the refugee displacement of diverse populaces disempowers the impact of borders, evident in the 2016 migratory mapping of refugees across Europe ${ }^{1}$ as the war against COVID-19 re-entrenches borders, military presence, fear and isolation and while the economically disempowered suffer most.

Contributing factors are attributed to the constantly widening economic disjuncture between the 'haves' and the 'have nots'. In purportedly 'postcolonial' environments, this contemporary social fissure appears vested across race, gender, sexuality, religious persuasion and ethnicity. Frequently mobility lies in the individual's post-colonial quest to reinvent narrative, agency and voice. Hence the particular relevance of Ashwin Singh's themes in this anthology. To House focuses on socio-economic mobility (23-70). There is a preoccupation with Islamic terrorism in the face of impending internal South African revolution in Duped (71-116). The internal strife threatened by current rising unemployment alludes to an almost prophetic prediction as we learn of current looting of trucks and shops during the South African lockdown. Corporate take-overs control the conclusion in Spice'n Stuff (117-162) and this too is echoed as we watch small businesses being swallowed up by corporate giants lucrative enough to survive a pandemic and online shopping being prioritised this year. In Reoca Light, the demise of the African dream is evident (163-186), and remains on our trajectory as we face the onset of a global economic depression post-COVID-19. Finally, the consequences of changing landscapes for women and the effects of a helplessly flailing education are covered in Beyond the Big Bangs (187-220). Even in this final

1 www.bbc.com/news/world-europe-34175795 [Accessed: 14 June 2019] 
astute acknowledgement the reverberations are real with education resorting to remote learning in South Africa and an estimated $66 \%$ unable to access the learning distance channels provided, therefore confirming that although influenced by society, playwrights in reflection influence society allowing communities to grapple with new complexities.

\section{South African Thematic Shifts}

Each theme in Singh's work is counterpoised against an understanding of preconditions in South Africa. Racial restrictions in terms of area, employment, and relationships are explored in To House (H 23-70). The revolutionary redefinition of hegemony, broached in Duped, assumes comparative analogies with a quasiNazi heritage (D 71-116). The demise of 'corner shop' individuality and crafted uniqueness, in favour of the emergence of business giants and monopolies in Spice ' $n$ Stuff, signify a corporate control powerful enough to squeeze out the smaller fish, thereby continuing the disenfranchisement of the past (SS 17-162). Past hopes of indentured Indians are juxtaposed against the ingrained violence, the bitter guilt and regrets and the disempowering suspicions and conditions left behind by an aggressive apartheid regime in Reoca Light (RL 163-186). The intra-cultural fusion and dislocation of roots indicates urban dissatisfaction that prompts suburban relocation in Beyond the Big Bangs (BBB 187-220).

Singh as playwright flexes the irony of each moment, with dialogue laced in sardonic humour. Here business and ownership of the economy is fronted in Deena's exit line in scene 11 which stings while ringing at Jason's ineptitude: "Let's see if you can construct a strategic projection, like a manager would" (H 64) or Sibusiso's accusation that acknowledges Jason as a fired thief: "Ah shame. You brought in so much money you had to steal some" (H 69) and the later play on this when Jason accuses Sibusiso of stealing [whites'] jobs and Sibusiso's response: "Steal[ing] our jobs. In the company from which you stole? ... You're used to a certain lifestyle" (H 69). Archetypal characters allow readers, actors, directors and audience to easily recognise peripheral phenomena. In reading the anthology as a literary text we conclude that the social movement that prompts the reconstruction of identity and community, re-inscribes the negotiations of race, culture and gender. Reverting to the legacy of assimilation and colonial-styled hegemony allows us to glance beyond the stereotypical caricature and intended cliché, as perception takes us back to the character as political, or inscribed by the 'polis' environment. Thus, through evaluating the nostalgic dream as well as the realities of 'being African', the plays confront us with the license of freedom. Singh acknowledges that as South Africans we are attempting to renegotiate boundaries and borders previously legally entrenched. His critique notes that the constitution is central to dismantling the fascist legal system, but has this left 
everyone unprotected? The fences do not come down. The walls are built higher, and protection remains the domain of the wealthy. In South Africa - the $20^{\text {th }}$ Century embodied by segregation, intolerance and alienation - was perceived as globally, nationally and locally dysfunctional. Hence the need for reflection. Ashwin Singh's anthology of five works, Durban Dialogues, Indian Voices is a $21^{\text {st }}$ Century reaction to the incumbent complications inherent in this dysfunction as well as the world beyond.

In place of the entrenched national frontiers of the $20^{\text {th }}$ Century, the $21^{\text {st }}$ Century proposes the break-down of narrow definitions of culture, religion, gender and sexual orientation without preparing for the inherent complications. Towards the close of the $20^{\text {th }}$ Century, restrictions were internally deconstructed prompted by the freedom communicated across internet. Movements defied confinement, and enlightenment embraced global inclusivity - as distinct from global assimilation, so what went wrong? Acclaimed South African playwright Mike van Graan, in response to what needs to be communicated in contemporary society and the potential global analogies, answers:

We are a society in transition, with all the tensions, anxieties, hopes and possibilities attached to that. Our theatre, art and literature - in my view - need to be exploring these, helping us through this transition. We live in a globalised world, impacted upon and impacting on the world around us, so that our theatre also needs to be interrogating ... exposing the relationship/s between the individual and the collective, the micro and the macro, the national and the international through human stories. I'm not sure what constitutes a 'global' voice, as theatre needs to be doing this for its individual, specific contexts and should this resonate with situations elsewhere, this becomes global. (Lutge, 2016c)

The transmigration and the shutdown of the $21^{\text {st }}$ Century goes further taking the internal re-evaluation of identity across physical facades, confronting the masks, and questioning the ethos of change in a world of economic re-alignments. Frontier crossings, border closures, socio-economic disparities, diffusing cultural enclaves all predetermine the future effects of marginalisation, memory, historical reading and contemporary context. The past provides a confused mapping of prevailing conditions that evidence an allusion to contemporary concomitant shifts. This raises questions centred on the sphere of influence of $21^{\text {st }}$ Century writers and directors as the canvas for writers and directors moves to embrace the internationalisation of texts: literary and performance. Malika Ndlovu sees "... the local and specific as the primary creative site from which universal relevance and resonance emerges" (Lutge, 2016b); Shantal Singh seeks the authentic South African voices exploring "an evolving, democratic society ... rich in cultural tapestry". Singh bemoans the "over-proliferation of Eurocentric work" connoting foreign values as well as the divisiveness of language materialising as inhibitors of "dialogue driven" theatre. 
She further asserts that: "We clearly need to communicate with each other ... [as] theatre should be seen as the window to our souls" (Lutge, 2016e).

Es'kia Mphahlele in The Tyranny of Place and Aesthetics talks to the "inhibiting effects" that the separation from South Africa had on constructing the Struggle writer's literary landscape (Naidoo, 1997: 251). Mphahlele notes the trauma of grappling with African identity, while in exile. Mda too, notes democracy as the dirge for some playwrights and storytellers, reliant on political activism, social realism, and documenting historical hegemonies in order to conscientise audiences, through socio-cultural awareness. Conversely Zakes Mda in an interview with Venu Naidoo for Alternation, argues for the imaginative process and the global influences garnered in reading widely from Gibson Kente and Wole Soyinka to Joe Orton or Harold Pinter. He concurs that there are elements of absurdism as well as postcolonial magic realism in his work. Mda avers that in confronting so called "objective reality" he wrote about "the world that I created". He explains: "I am in the God business. I am the God of that world, so I can make things happen the way I want them to happen" (Naidoo, 1997: 250).

\section{The Anthology in Context}

The paradigms, as evidenced above, dictate an eclecticism infused with transnational narratives, intracultural fusion-styled structure, and a perspective advocated by the contemplation of the disjuncture between diaspora (migration) and milieu (environment), and the seemingly controversial effects of COVID-19 on communities unable to socially distance due to informal settlements and their dismal living conditions. This reflects Singh's prophetic writings and is the stuff of Ashwin Singh's Durban Dialogues, Indian Voices. Further in Singh's writings there is a search for identity, for 'I-content' - a term, not located in notions of Ubuntu - but coined for this chapter to agglomerate the ' $\mathrm{I}$ ' as in 'me' and the digital attempt to cater to our demand for immediacy, entitlement and the ability to access personal freedom as well as the changing continuums perceived in pandemic isolation as well as in To House. These traits of entitlement are visible in the closing moments of the play during Sibusiso's accusation of the social façade, of keeping up appearances by shopping at exclusive malls because: "Taking money from a big firm is okay. It's the way you were brought up. You were always given everything ... You had an economic system designed to make you rich.” (H 70). The repetition of greed is compounded further through Sibusiso's final acknowledgement that his aspirations extend to encompassing everyone else's goals as body corporate chairman, senior lecturer, expert on informal settlements invited to speak to issues on national television, and world famous personality reclaiming the world Jason lost (H 70). (see Conquergood, 2002: 145, citing Gilroy, 1994; Appadurai, 1996; Lavie 
\& Swedenburg, 1996; Cliffard, 1997; di Leonardo, 1998; Joseph, 1999; Ong, 1999; and Taylor, 1999).

I contend that this ownership of the uniquely conflicted South African world, evident in Singh's writings, is because it is a world of trauma in which the stakes are raised through excessive levels of violence, anger and guilt. This search for transparency, this quest to reposition 'other', this profundity inscribed in positioning humanity as teetering amidst the smoke on the edge of survival, raises the stakes and makes social pulses surge. The post-apartheid anti-climax, suggests drained intensity, and the junkie's nervous malaise or a numbed indifference - perhaps the kind that writers in exile seem to have experienced. Could this sense of loss, this loss of contact account for activists such as Mphahlele sensing a disengagement with their African identity? How does this contention align with Mda's concerns that writers are creating less with the easier lifestyle of democracy? Is this the reason that current activists, who interrogate the effects of the past on democracy, have not lost their creative impulse? Ashwin Singh alleges that

issues ... prevalent in our local communities ... inevitably have universal significance because people all over the world have so many common experiences, challenges, triumphs and tragedies. Theatre ... is far less corporate than film and therefore should provide the opportunity to create memorable works of art ... I believe we have a particular responsibility in contemporary South Africa to tell local stories and to prioritise these ... Apartheid obliterated Black culture in all its forms...it considered our art and other cultural expressions second rate ... so we have to expose this lie with more vigour and passion. We truly need an African Cultural Revolution. (Lutge, 2016a)

In Singh's work the continual realigning of perspectives, predetermined by the reader or viewer's new discoveries, is invited through the conflict endorsed by what might be termed the interaction of sacrosanct socio-cultural and political enclaves and the irony invoked in shifting local, national and global assimilation policies. The juxtaposition forces a confrontation of who, what, where, when, and why it is necessary to express ourselves as reinvented humans. The image in motion reflecting back from the sky on the specks that are us in Duped moves us to re-interrogate notions of the ever-widening gaps. Reconciliatory Ubuntu attempting to redefine social mores amidst the widening economic chasm smacks of fantasy.

The writer, the director, and the audience in South Africa inevitably encompass linguistic, socio-cultural, spiritual, political, racial and gender diversity straddling pasts filled with racial prescriptiveness, distinctive socio-economic experience, and vastly divergent political landscapes that are evident now, during lockdown, more than ever before. Director Ralph Lawson contends that: "we are a magnificently polyglot society, and our stories need to reflect this. I would say that this is the feature which mainly sets us apart from global voices" (Lutge, 2016d). 
So if the writer belongs to one diverse grouping how is this negotiated in the conceptual translation from literary to performance text? Mike van Graan notes significantly how collaboration impacts product: "Casting is probably the key element in how one's text is viewed. The more technically skilled, experienced and 'branded' the actors (and director), the better the text is interpreted and presented" (Lutge, 2016c).

\section{Sociocultural and Political Constructs}

By implication, therefore, the theatrical archetype itself supersedes sociocultural and political constructs, albeit that the choice to collaborate may indeed be influenced by common criteria within the polyglot society or the method of delivery. Therefore, notwithstanding the diverse influences and contexts, the transmigration that occurred in protest theatre collaborations, notably: Kani, Ntshona and Fugard's theatre; Purkey's Junction Theatre plays; or Ngema, Mtwa, and Simon's works; intracultural reflection is evident in Singh's contemporary writer and director collaborations mounted by a series of directors from racially and culturally diverse backgrounds. The directors included among others: Themi Venturas directing Spice ' $n$ Stuff at the Playhouse Loft (2010) and at the Sandton Theatre on the Square (2011); Ralph Lawson directing Reoca Light at the Loft (2017); To House in the Drama (2017) and Into the Grey in the Loft (2018) at the Durban Playhouse Complex and Reoca Light (2019) at the Tara Theatre in London; Edmund Mhlongo directing Culture Clash (2013) at the Loft; Caroline Smart directing To House at the Playhouse (2006) and Spice ' $n$ Stuff at the Catalina Theatre (2007); Debbie Lutge directing Duped at the Courtyard Theatre (2017); as well as the writer himself directing Beyond the Big Bangs (2016). Inscribed in Singh's writing too, is the recognition of a single national imperative in order to reconnect across social divides, as well as to extend across borders in line with internationalisation trends. This signifies globally connecting contexts, by inviting and encompassing multi-layered perspectives, acknowledging the shift away from tunnelled world-views grown in isolation, whether internally or externally constructed. Three centuries of South African Struggle under colonialism provides a paradigm that pre-empts and yet is intricately woven in British Prime Minister Harold Macmillan's 'Wind of Change'2 parliamentary debate, delivered on 3 February 1960 in Cape Town. So our inevitable South African theatrical syllogism coined by $\mathrm{Mda}^{3}$ could arguably be reconstituted as 'the past is dead, until memory is the author', providing an authorial catalyst for future global literary direction as Europe faces the $21^{\text {st }}$ Century refugee crisis or the world fights a global pandemic.

2 https://www.sahistory.org.za/article/wind-change-speech [Accessed 14 June 2019]

3 "Now the author is dead, and the author is Apartheid" Zakes Mda (quoted in Naidoo, 1997: 252) 


\section{The Chicken - Egg Paradox}

Both directors and audiences read texts differently as the conscious choices of the director evolved in rehearsal process are frequently only unconsciously experienced as audio-visual stimuli by audiences. Theatre patrons simultaneously interpret - in a single sitting - content as well as directorial framing. Textual writing, reading and reception, influenced by the literary medium versus the production experience, confirm the variance in the literary and performance text debate. Audiences attending Shakespearean productions frequently attempt to battle their way through a literary text that, once mounted or placed in celluloid, enable the form to be read in much the same way as an advert hints subliminally at associated influences. Conversely Amy S. Green in The Revisionist Stage: American Directors Reinvent the Classics addresses the supplanting of authorial voice and the emergence of the 'director-author'. Shantal Singh, answering a questionnaire I circulated to selected practitioners, refers back to the 'authenticity' of voice inscribed in the original vision. Yet, once a playwright confers rights, the writer is effectively powerless, if the reinterpretation of text is subject to an erudite directorial interpretation and the production based on empirical observation, critical analysis, and what Conquerwood calls "a distanced perspective" (Conquerwood, 2016: 146). He concurs that propositional knowledge "anchored in paradigm and ... print" is thereby juxtaposed against practice anchored in ephemeral context, whether envisioned in the writing or not. Hence the 'chicken or egg' primacy paradox. The creative director strives to resonate between text and audienceexpectation and, as Ashwin Singh contends, "realize the action and ... emotion ... [as well as] ensure a rhythm" (Lutge, 2016a). The relationship between writer and director is a mutually influential one, and it is the critical detachment that is the key to a solid working relationship. Ralph Lawson describes it as "a tricky mix" inscribed with "trust on the part of the writer who surrenders control", followed by confidence in the expertise of a skilled director capable of providing "another eye on the work ... and [Lawson asserts] isolation and objectivity can unearth a number of points of which the playwright was perhaps only subconsciously aware" (Lutge, 2016d). In Theatre Directing in South Africa, Durban writer-director Neil Coppen claims his theatre apprenticeship left him fascinated by the concept of 'total theatre' where “ ... visual symbols and elements [are] as seminal as the text ..." (quoted in Twijnstra \& Durden, 2013: 16). This asserts the need for the writer/director to visualise the potential of the text in motion and, where the writer directs their own work, it is the realisation of this visualised concept that prompts many writers to grapple with the first staging of their untested text. South African theatre-entrepreneur, Greg Homann, holds that theatre in South Africa "is director driven" and "rarely driven by the writer or producer" (quoted in Twijnstra \& Durden, 2013: 22-24). As an arts entrepreneur, Homann, inspired by Malcolm Purkey - whom he avows was the director that "conscientized him into the complexity of South Africa [...] almost always finds the projects rather than the 
project finding him" (quoted in Twijnstra \& Durden, 2013: 22-24). Lunacharsky in "Theses on the Problems of Marxist Criticism" contends:

Our literature is passing through one of the decisive moments in its development. A new life is being built in the country, and literature is learning more and more to reflect this life in its as yet undefined and unstable forms; evidently, too, it can pass to a problem of a still higher order - to the political and, in particular, the moral influence on the very process of construction. (cited in Dukore, 1974: 949)

Having noted many of the paradoxes inherent in this debate, centred on creative hegemony, a further complication derives from the critical detachment of the subject matter embraced in the initialising work of the director. If the writer alone authenticates the voice does this propose limitations for future productions? Or does reinterpretation run the supplementary gauntlet of frequent misinterpretation? Does the writer's careful negotiation of the initial mounting guide future mountings, expectations, or critical reception? In translation, how are bridges forged and is this gap the responsibility of the literary text or the performance text?

Yes, there is a huge difference between how a text is reviewed as a literary piece on the one hand and as a performance piece on the other. The literary piece stands on its own, and is evaluated as a piece of literature/writing. A performance gives life to the text and the evaluation/reviewing evaluates not just the text, but the performances, the directing, the design, etc - the full, holistic presentation of the theatre piece. This is as it should be. (Lutge 2016c)

\section{Conclusion}

In a $21^{\text {st }}$ century post-colonial setting, both director and playwright reinvent the wheel, treat the reconditioning, transform the angles, and merge the historical reflection. Benedetti in The Director at Work (1985) distinguishes broadly between the "conservative position", seeking "fidelity" to the text, the "liberal position", striving for "relevance" of the interpretation of the text, and the "radical position", evidencing creativity derived from the text (Benedetti, 1985:13-16). However, this does not mean that these categories necessarily align with literature, although literature would seem to be constructed along three broad lines too: first, traditional lines; second, re-constructed or recontextualised lines, informed by the contemporary socio-cultural or political perspective; third, deconstructed lines that, by drawing on and rereading tradition, deviate or reflect upon the implied messaging and associations (see Silverman, 1989: 2).

As narratives around live theatre are reimagined globally with current theatre closures due to COVID-19, concomitant unemployed artists seeking to reimagine 
theatrical possibilities under new social distancing auditorium and performance requirements, as well as the regulations governing the imperatives of donning public masks, means distanced audiences impacting already dwindled ticket sales in South Africa. Will this consequent effect on salaries, further prioritise the compacting of the role of writer-directors and solo or minimal cast performances in the immediate future? Certainly it will pose challenges for unestablished writers and directors entering a newly imagined arena where the economics of mounting plays with rising ticket prices and contained fragmented, audiences derives less sponsorship and investment in the youth than needed. The question this raises is one of continuing negotiation.

Albeit the overlapping mapping of rhythmic patterning between writer and director may either converge or diverge, there remains a constant distinction between both the writer and director's processes. The directorial vision lies in the immediacy of the directing process, while the literary text gravitates towards the permanence of the written publication, and yet both are considered process as well as product-driven activities. The result of the chicken/egg textual recipe, is an exposition of our human narratives. Ashwin Singh's concern with embracing this South African voice explores who we are and how we connect in the literary text as well as in the mounted production.

In conclusion, the encapsulation of Ashwin Singh's works, are perhaps best epitomised in this Mahatma Gandhi quote:

I do not want my home to be walled in on all sides and its windows to be stuffed. I want cultures of all lands to be blown about my house as freely as possible. But I refuse to be blown off my feet by any (quoted in Mehta, 2000: 630).

\section{Bibliogranhy}

Appadurai, A. 1996 Modernity at Large: Cultural Dimensions of Globalization. Minneapolis: University of Minnesota Press.

Benedetti, R. L. 1985. The Director at Work. New Jersey: Prentice Hall.

Bharucha, Rustom. 1993. Theatre and the World: Performance and the Politics of Culture. London: Routledge.

Clifford, J. 1997. Routes: Travel and Translation in the Late Twentieth Century. London: Harvard University Press.

Conquergood, Dwight. 2002. Performance Studies: Interventions and Radical Research. TDR/The Drama Review, Vol 46.2, 145-156. Summer 2002. New York, NY: New York University and the Massachusetts Institute of Technology. https://doi. org/10.1162/105420402320980550

Di Leonardo, Micaela. 1998. Exotics at Home: Anthropologies, Others, American Modernity. Chicago: University of Chicago Press.

Dukore, Bernard, F. 1974. Dramatic Theory and Criticism: The Greeks to Grotowsky. New York, NY: Rinehart and Winston.

Fénelon, François. 1825. Abrégé des vies des anciens philosophes, Paris 1726: 314. Translation: Lives of the Ancient Philosophers, London 1825: 202. 
Gilroy, Paul. 1994. After the love has gone: Bio-politics and etho-poetics in the black public sphere, Third Text, 8 (28-29): 25-46. https://doi.org/10.1080/09528829408576500

Govinden, D.B. 2013. A Critical Overview. Ashwin Singh's Durban Dialogues, Indian Voice: Five South African Plays. Twickenham, UK: Aurora Metro Books.

Green, Amy S. 2006. The Revisionist Stage: American Directors Reinvent the Classics. Cambridge Studies in American Theatre and Drama. Vol 3, 1-244. reprint New York: Cambridge UP.

Hodgson, Geoff. 1986. Behind methodological individualism, Cambridge Journal of Economics, 10 (3) September: 211-224. https://doi.org/10.1093/oxfordjournals.cje.a034996

Johnson, W. R. 1994. Dismantling apartheid: A South African town in transition. The Anthropology of Contemporary Issues, August 4. Ithaca: Cornell UP.

Joseph, M. 1999. Nomadic Identities: The Performance of Citizenship. (First edition ed.). Minneapolis: University of Minnesota Press. muse.jhu.edu/book/32163.

Kholofelo, Sedibe. 1998. Dismantling Apartheid Education: an overview of change. Cambridge Journal of Education, 28 (3), November: 269-282. https://doi. org/10.1080/0305764980280302

Lavie, Smadar \& Swedenburg, Ted. 1996 Between and among the boundaries of culture: Bridging text and lived experience in the third timespace, Cultural Studies, 10 (1): 154-179, https://doi.org/10.1080/09502389600490501

Lee, I. C., Pratto, F., \& Johnson, B. T. 2011 . Intergroup consensus/disagreement in support of group-based hierarchy: an examination of socio-structural and psycho-cultural factors. Psychological Bulletin, 137(6), 1029-1064. https://doi,org/10.1037/a0025410

Mehta, P, B. 2000. "Cosmopolitanism and the Circle of Reason". Political Theory, 28 (5), October: 619-639. Sage Publications, Inc. Stable, http://www.jstor.org/stable/192291_

Migrant crisis: What next for Germany's asylum seekers? - Section Europe. 2015. BBC World News. 14 September. http://www.bbc.com/news/world-europe-34175795_

Mulgan, R.G. 1974. Aristotle's Doctrine That Man Is a Political Animal. Hermes, 102. Bd., H.3, Franz Steiner Verlag: 438-445. http://www.jstor.org

Naidoo, Venu. 1997. Interview: Interview with Zakes Mda. Alternation, 4(1): 247-261.

Ong, A. 1999. Flexible Citizenship: The Cultural Logic of Transnationality. Durham: Duke UP.

Rospide, Maylis and Sandrine Sorlin. 2015. The Ethics and Poetics of Alterity: New Perspectives on Genre Literature. Newcastle upon Tyne: Cambridge Scholars Publishing.

Segal, R. 1964. Sanctions Against South Africa. Harmondsworth: Penguin.

Silverman, D. 1993, 2001, 2006. Interpreting Qualitative Data: Methods for analysing Talk, Text and Interaction. Ed. 3. London: SAGE Publications

Singh, A. 2013. Durban Dialogues, Indian Voice: Five South African Plays. An Anthology. UK: Aurora Metro Books.

Simons, J. 1997. Drama Pedagogy and the Art of Double Meaning. Research in Drama Education: The Journal of Applied Theatre and Performance, 2 (2): 193-201. Published online: 07 Jul 2006. https://doi.org/10.1080/1356978970020205

Taylor, C. 1999. Democratic exclusion (and its remedies?). In: A Cairns, J. Courtney, P. MacKinnon, J. Michelmann, and D Smith (eds). Citizenship, diversity, and pluralism: Canadian \& Comparative Perspectives. Montreal: McGill-Queen's University Press, 265-287.

Twijnstra, Roel \& Emma Durden. 2014. Theatre Directing in South Africa: Skills and Inspirations. SA: Jacana Media

Waller, D. 1998. The Chicken and Her Egg. Mind, 107 (428): 851-853. www.jstor.org/ stable/2659791 
Emails:

Lutge, D. A. 2016a. Unpublished Interview with Ashwin Singh. Generated on email on: 7 May 2016.

Lutge, D. A. 2016b. Unpublished Interview with Malika Ndlovu. Generated on email on: 27 May 2016

Lutge, D. A. 2016c. Unpublished Interview with Mike van Graan. Generated on email on: 27 May 2016

Lutge, D. A. 2016d. Unpublished Interview with Ralph Lawson. Generated on email on: 27 May 2016

Lutge, D. A. 2016e. Unpublished Interview with Shantal Singh. Generated on email on: 27 May 2016

Lutge, D. A. 2016f. Unpublished Interview with Steven Stead. Generated on email on: 27 May 2016

Lutge, D. A. 2016g. Unpublished Interview with Themi Venturas. Generated on email on: 27 May 2016. 